\title{
Evolution and the Myth of Creationism
}




\section{Tim M. Berra}

Department of Zoology

The Ohio State University

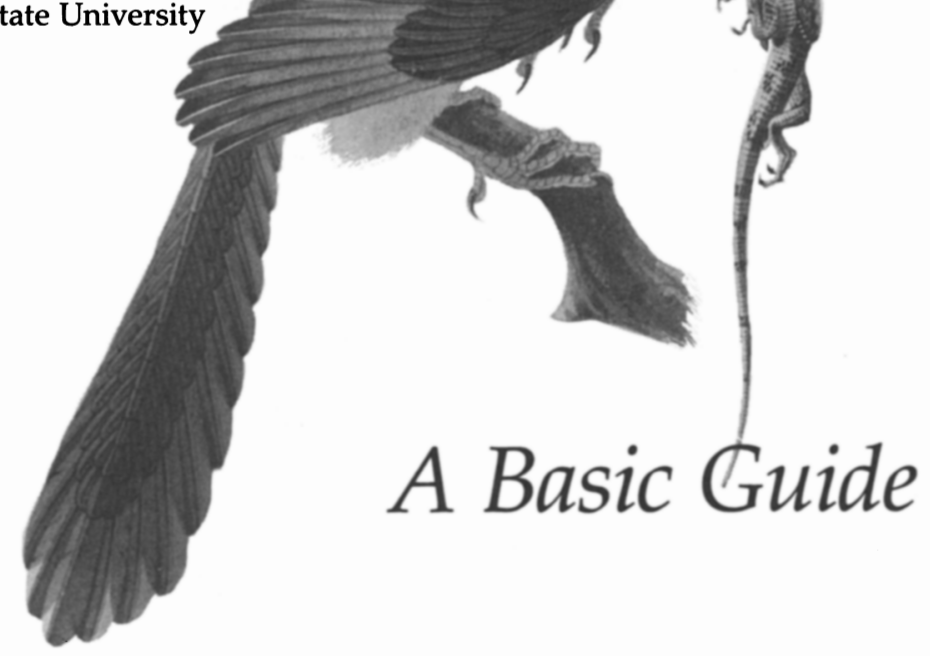




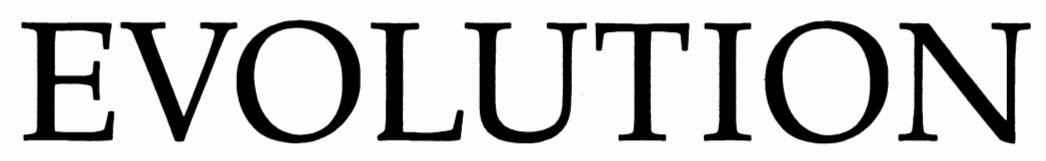

and the Myth of

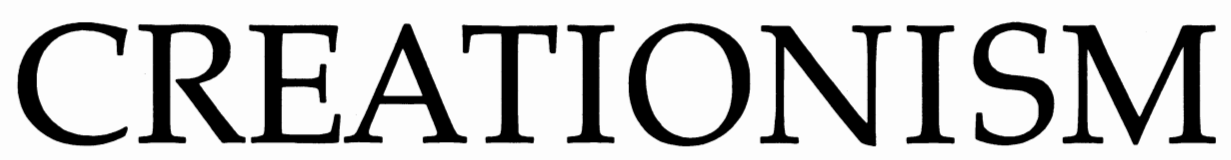

to the Facts in the Evolution Debate

Stanford University Press, Stanford, California 
Stanford University Press

Stanford, California

(C) 1990 by the Board of Trustees

of the Leland Stanford Junior University

Printed in the United States of America

Original printing 1990

Last figure below indicates year of this printing:

$\begin{array}{lllll}07 & 06 & 05 & 04 & 03\end{array}$

CIP data appear at the end of the book 
FOR MY MOTHER,

who allowed me to read during meals 
